\title{
Hochstapler und andere
}

Erhard Taverna
Vier Medizinbücher, die gute Unterhaltung, aber keine Kreditpunkte garantieren. Ein Schelmenstück von Kaspar Wolfensberger mit dem bestens eingeführten Doktor Zangger aus Zürich, ein Krimi von Robert Vieli mit dem erfolgreich ermittelnden Kommissar Fürbass aus Chur, ein kosmischer Wettkampf von Yves E. Patak um das Leben eines Schönheitschirurgen und eine Kurzgeschichtensammlung mit Themen des Gesundheits(un)wesens.

\section{Der Seelenwexler}

Temporeich und überaus witzig erzählt Kaspar Wolfensberger von seinem «alter ego», dem Psychiater Zangger, von dessen Fluchtort Afrika und einem zwielichtigen Praxisstellvertreter, von dem es im ersten Satz heisst: «Fast alles an ihm war fake.» GionGieri Caduff, der sich in Zürich lieber Phil oder Dr. med. Wexler nennt, ist ein talentierter Hochstap-

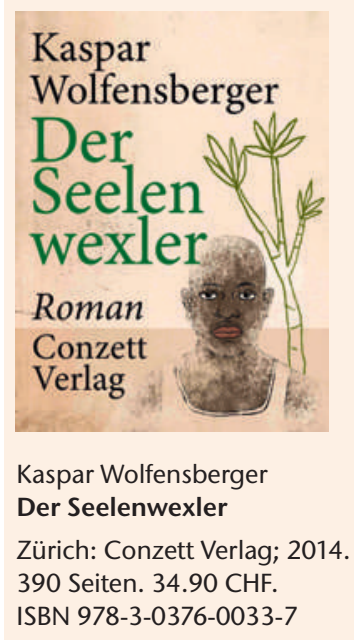

ler, der äusserst erfolgreich das Burnout seines Therapeuten Zangger zu seinen Gunsten ausnützt. Noch im offenen Strafvollzug befindlich, kann der Laie Caduff bei seinen erschwindelten Patienten sagenhafte Erfolge verbuchen, die jeden echten Arzt herausfordern müssen. Wo gibt es das schon: ein Multitalent, dem die vielen Verführungsopfer, auch nach der Entlarvung, dankbar verbunden bleiben. Kaspar Wolfensberger hat mit dieser Figur einen Falschspieler eingeführt, von dessen brillanten Ideen, enormem Selbstvertrauen, gutem Aussehen, Charme und hoher Risikobereitschaft sich wohl jeder eine Portion abschneiden möchte. Geschickt konstruiert und spannend erzählt, bietet der Autor ein humorvolles Lesevergnügen, mit zahlreichem Personal, das Leserinnen und Leser zu wechselnden Identifikationen verlockt und uns über verschlungene Pfade, hintersinnig und intelligent, einen Spiegel vorhält.

\section{Demontage eines Politikers}

Isidor Eichhorn wird zum ersten parteiunabhängigen Nationalrat Graubündens gewählt. Arrogant und skrupellos, finanziell sehr erfolgreich, blamiert er die etablierten Parteien und blendet seine Wähler mit populistischen Parolen. Der politische Quereinsteiger wird als chaotischer Einzelgänger zum nationalen Medienliebling. Endgültig in alle Schlagzeilen gerät er nach der verdächtig spät erfolgten Vermisstenanzeige seiner verschwundenen Ehefrau Clelia. Schweigsame Dorfbewohner, Wirtschaftsfilz und Politklüngel der spezifisch bündnerischen Art erfor-

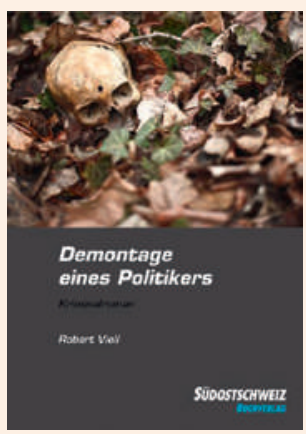

Robert Vieli

Demontage eines Politikers

Glarus: Südostschweiz Buchverlag; 2014.

304 Seiten. 29.00 CHF.

ISBN 978-3-906064-20-8

dern viel Taktgefühl und Spürsinn von Kommissar Fürbass und seinem Assistenten Casanova. Die erste Spur ist ein blanker Schädel, an dessen Fundort die Rhätische Bahn einen Extrahalt für die Experten aus der Hauptstadt einlegen muss. Mit treffenden Dialogen und typischem Lokalkolorit treibt Robert Vieli die Ermittlungen voran. Ein eigenwilliger Kommissar, trocken wie der berühmte Maluns, lässt auch einmal krumm für gerade durchgehen, wenn es der Gerechtigkeit dient. Denn ganz lupenrein ist die Sache nicht, wenn der Hochstapler endlich zu Fall kommt. Aber recht geschieht ihm, und Fürbass hat seine Pizza verdient. 


\section{Himmel und Hölle}

Er habe sein Buch für Urlaubsleser geschrieben, sagt Yves E. Patak seinem Interviewpartner in einem Film auf YouTube. Marcel Dumont, wie ein Mann aus der Coca-Cola-Werbung, rast mit einem knallgelben Lamborghini-Cabriolet von seiner Villa in das Zürcher Niederdorf, wo er, wie immer, falsch parkiert. Der prominente Schönheitschirurg der Hedona-Privatklinik am See führt das Leben eines Grossverdieners

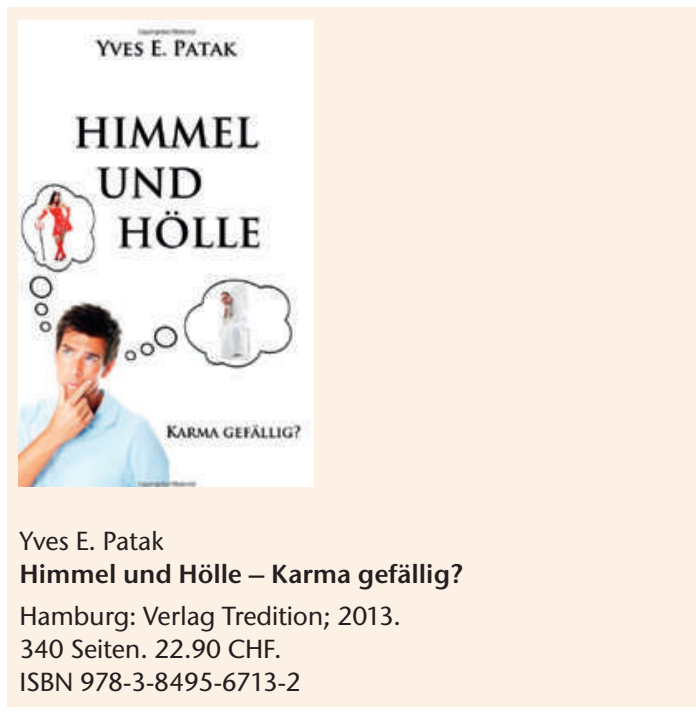

und potenten Schürzenjägers, arrogant, zynisch und genusssüchtig. Um den Playboy streiten sich Ionel und Shanty, berufen von höchster respektive tiefster Stelle. Genaueres sei hier nicht verraten. Yves E. Patak jongliert variantenreich alle Klischees, die sich mit dem Beruf des Schönheitschirurgen und einer testosterongetriebenen Existenz verbinden. Der Thrillerautor beweist dabei einmal mehr seine reiche Fantasie für übersinnliche Konstellationen und karmische Umwege. Das alles ist schmissig erzählt, erotisch gut gewürzt und mit einem Augenzwinkern aktionsreich komponiert. Unterhaltend auf jeden Fall. Mit einem überraschenden Ende.

\section{Diagnose Mord}

Eine Sammlung von Kurzgeschichten aus dem gestörten Räderwerk zeitgenössischer Therapiebetriebe. 17 Autorinnen und Autoren berichten von Habgier, Pfusch, Grössenwahn, Kunstfehlern und weiteren Pathologien des medizinischen Alltags. Jeder Fallgeschichte folgt ein kurzer, sachkundiger Kommentar der promovierten Rechtsmedizinerin und Schriftstellerin Ulrike Blatter; ergänzend, belehrend, humor-

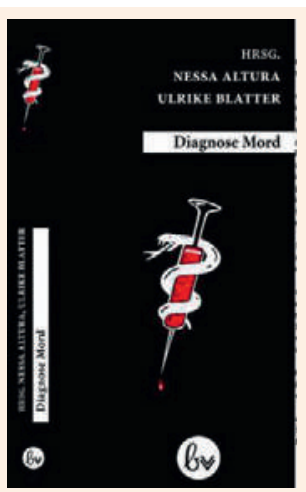

Nessa Altura, Ulrike Blatter (Hrsg.) Diagnose Mord

Zwickau: Buchvolkverlag; 2014.

304 Seiten. 18.90 CHF.

ISBN 978-3-9445-8101-9

voll, oft untermalt mit einer eigenen Klinikgeschichte aus ihrer vielseitigen Tätigkeit. Auf der kriminellen Geisterbahn begegnen wir fast allen Gesundheitsberufen und Fachrichtungen. Und weil der Medizinbetrieb getreulich die Gesellschaft spiegelt, ist nicht immer klar, an welcher Türe der normale Wahnsinn beginnt oder endet. Die Buchanzeige warnt vor Nebenwirkungen wie Gänsehaut, geistige Verwirrung oder akute Hypochondrie. Ganz so schlimm wird es beim Zuhören dieses vielstimmigen Gruselchors leider nicht. Denn nicht jede Stimme ist hier arientauglich, doch als Teil eines Ensembles allemal eine willkommene Verstärkung. 